\title{
Evaluation of Epidemiological Factors of Radiological Imaging Methods in Thoracoabdominal Trauma Patients
}

\author{
(D) Figen Tunalı Türkdoğan¹, (1) Abuzer Coșkun²
}

${ }^{1}$ Bahçelievler Physical Therapy and Rehabilitation Training and Research Hospital, İstanbul, Turkey

2 Department of Emergency Medicine, University of Health Sciences Turkey, Bağcılar Training and Research Hospital, İstanbul, Turkey

\begin{abstract}
Aim: Traumas continue to be the leading cause of death in healthy adults presenting to emergency services worldwide. This study aimed to analyze the epidemiological causes of life-threatening thoracoabdominal traumas.

Materials and Methods: One thousand and one hundred and twenty-one patients older than 18 years of age who presented to the emergency service due to trauma between January $1^{\text {st }}, 2017$, and December $31^{\text {st }}, 2019$, were included in this retrospective study. Traumas were grouped as falls, traffic accidents and penetrating injuries. Five groups were also formed according to radiological imaging methods.

Results: Mean age was $35.80 \pm 16.15$ years in in-vehicle accidents and $46.56 \pm 17.64$ years in penetrating injuries $(p=0.001)$. It was found that $847(75.6 \%)$ of the cases were falls, 222 (19.8\%) were traffic accidents, and 52 (4.6\%) were penetrating injuries. Sixty-seven (\%6) of the cases underwent ultrasonography in falls from higher than $2 \mathrm{~m}, 399$ (35.6\%) of the cases underwent direct X-ray in falls from lower than $2 \mathrm{~m}, 9$ (0.8\%) cases underwent abdominal computed tomography (CT), 19 (1.7\%) cases underwent multiple imaging in non-vehicle traffic accidents, and 24 (2.1\%) cases underwent thoracic CT in falls from higher than $2 \mathrm{~m}$. In the analysis of trauma types with variables, positive low and moderate correlation was found in all variables except for age.

Conclusion: Mortality and morbidity rates can be reduced by an early multidisciplinary approach to trauma cases and early decision of radiological imaging procedures to be carried out.
\end{abstract}

Keywords: Emergency service, epidemiology, trauma, mortality, radiological imaging

\section{Introduction}

Traumatic injuries cause undesirable workforce loss and even deaths in young and productive age group $(1,2)$. The first hour following trauma is the golden time and it has a critical importance in preventing morbidity and mortality in the first 24 hours (3). For an urgent and comprehensive intervention to injured individuals following trauma, a good organization is required in the area they are in and in the hospital. Trauma-related deaths occur in trauma area, hospital emergency service and intensive care (4).

Trauma clinic is very heterogeneous in terms of its underlying causes and it is characterized by injury types and severity. Uncertainty of prognosis is due to causes related with anatomical, professional, economic, political and cultural variables of risk factors (5). Trauma management before and inside the hospital requires a well-disciplined approach. Knowing about epidemiological factors ensures correct application of necessary algorithm in the management of trauma emergency approach. According to the data of World Health Organization (WHO); 29\% of traumas are causes by traffic accidents, while $12.6 \%$ are caused by falls and $9.16 \%$ are caused by individual accidents (6). These data may differ between countries and regions. In addition, the fact that traffic accidents are more common in men shows the difference in gender in trauma patients. In studies, one out of ten deaths is caused by trauma in both genders. Traumatic causes are the primary cause of death and disability in individuals under 
35 years of age. While penetrating situations such as traffic accidents, violence and self-harm are the primary causes of trauma in individuals between the ages of 25 and 35, this rate decreases after the age of 45 and blunt trauma mechanisms such as home accidents and falls come to the fore after the age of 45 (7). While head trauma is observed in the first place in fall-related accidents, this is followed by extremity traumas and abdominal traumas. Head traumas cause more morbidity and mortality with their permanent sequelae. The rates may differ between countries or regions in terms of socioeconomic development. Economic development rates also affect morbidity and mortality. The leading causes of mortality are neurological damage and haemorrhage. The primary cause of death especially within the first hours is haemorrhage $(4,8)$.

Penetrating trunk trauma is the second leading cause of death after head trauma $(7,8)$. In developed countries, traffic accidents, falls and general blunt traumas are the most common injury mechanisms, while penetrating trauma including gunshot wounds and stab wounds are most common in developing countries due to ongoing violence and social unrest (9). Penetrating chest and abdominal trauma have high mortality rates when important structures such as the heart, great arteries and liver are involved at the scene $(10,11)$.

Stabilization of the patient at the accident site prevents the patient's motor and sensory functions from getting worse. The leading cause of death is head traumas in-between the first and sixth days. Sepsis and multiple organ failure are longer term mortality causes of trauma $(3,4,12)$. Knowing the dynamic and risk factors of trauma allows for emergency interventions for fatal or permanent disability due to injury.

The aim of this study is to show the relationship of damage observed in thoracic and abdominal regions in causes of trauma due to different mechanisms and to show trauma risks caused by trauma dynamics. In addition, the rate of use of imaging methods related with trauma dynamic was also found in the study. Therefore, in the light of epidemiologic data obtained, it will be possible to improve prevalence and incidence information in trauma patients and more coordinated and multidisciplinary approaches will be possible.

\section{Materials and Methods}

\section{Study Design and Population}

One thousand and one hundred twenty-one patients older than 18 years of age who presented to the emergency service due to trauma between January $1^{\text {st }}, 2017$ and December $31^{\text {st }}$, 2019 were included in this retrospective study. Minor home and play accidents and cuts, isolated head-neck traumas and extremity traumas, patients who presented to the emergency service 48 hours after the trauma and those who did not undergo examination and imaging in the emergency service were excluded from the study. Trauma types and characteristics, radiological imaging, thoracic and minimal organ injuries of the patients were evaluated.

Traumas were divided into five general groups as falls [lower than $2 \mathrm{~m}(-2 \mathrm{mF})$ and higher than $2 \mathrm{~m}(+2 \mathrm{mF})]$, in-vehicle traffic accident (IVTA) and non-vehicle traffic accident (NVTA)], penetrating (piercing, cutting and firearm injuries) injuries (PI).

Five groups of thoracic traumas were formed as normal lung, right, left, bilateral and contusion. In addition, four groups were formed as absence of intra-abdominal organ injuries, spleen, liver and other (small and large intestine, kidney, ureter, etc.). The ribs were grouped in five as no fracture, single fracture, 2-3 fractures, flail chest and sternum fracture.

In the study, the patients with good and moderate general condition were evaluated in the trauma resuscitation room, those with poor coma score and consciousness level were evaluated in the emergency critic resuscitation room. Forensic forms were prepared for these patients, those who did not have tetanus vaccine had tetanus vaccine, those who required fluid and blood resuscitation were started fluid and blood resuscitation. All of the patients were recorded in the hospital automation and patient file records. Diagnoses, admission dates, communication information, demographic, clinical and laboratory data are in the registration system of our hospital.

Besides these, two groups were determined in terms of the presence or absence of thoracic vertebra, lumbal vertebra, hemothorax, pneumothorax, intraabdominal injury, artery injury and mortality.

\section{Radiological Imaging}

Patients who had good general condition, no thoracic and abdominal trauma, and who were thought to be bruised or have simple fractures and dislocations had direct X-rays. The patients who had stable general condition and vital signs underwent a thorough ultrasonography in the radiology unit. Patients with low coma score, poor general condition and instable vital signs underwent Focused Assessment Sonography for Trauma. The patients who were thought to have thoracic and/or lumbal vertebra fracture, thoracic injury, intraabdominal organ injury or haemorrhage and who could go to radiology unit underwent contrast and/or non-contrast computed tomography (CT). The patients who underwent multiple imaging were multiple trauma patients. These patients underwent imaging with the presence of a physician by taking 
resuscitation measures. All ultrasonography (USG) and CTs were analyzed jointly with radiology, emergency and related branch specialists.

After the study was approved by Clinical Researches Ethics Committee of Cumhuriyet University (decision no: 2019-12/22, date: 11.12.2019), it was carried out in accordance with Helsinki declaration for human researches.

\section{Statistical Analysis}

The data obtained from this study were analyzed with SPSS 20 (SPSS Inc., Chicago, IL, USA) program. Descriptive statistics were shown as mean \pm standard deviation or median (minimummaximum) for continuous variables, while nominal variables were shown as number of cases and percentage (\%). MannWhitney $U$ test and Kruskal-Wallis test were used while examining the differences between the groups. Chi-square analysis was used while examining the relationship between groups of nominal variables. Pearson correlation analysis was used for the linear correlation between the variables. Boxblot graph analysis was made for mortality, trauma and radiological imaging with age. While interpreting the results, values under 0,05 significance level were considered as statistically significant.

\section{Results}

Mean age of the 1121 patients was $41.17 \pm 16.65$ years with an age distribution of $19-94$ years and 379 (33.8\%) were female. Of the trauma patients, 436 (38.9\%) were $2 \mathrm{mF}, 411(36.7 \%)$ were $+2 \mathrm{mF}$,
36 (3.2\%) were IVTA, 186 (16.6\%) were NVTA and $52(4.6 \%)$ were $\mathrm{PI}(\mathrm{p}=0.001)$. Mortality was found in $23(2.1 \%)$ of the patients $(p=0.916$, Table 1$)$.

In terms of analysis according to trauma types, $+2 \mathrm{mF}$ was the most frequent in both genders. Mortality was most frequent in $+2 \mathrm{mF}$ with $11(1 \%)$ cases and NVTA with 7 (\%0.6) cases. Of the lung traumas, 105 (9.4\%) were in the right, 91 (8.1\%) were in the left and $18(1.6 \%)$ were bilateral. Contusion was found in $30(2.7 \%)$ of these cases. Twenty-five (2.2\%) of the patients were found to have lumbal vertebra lesion, while $15(1.3 \%)$ had thoracic vertebra lesion. Of all the cases, 28 (2.5\%) were found to have pneumothorax injury, while 19 (1.7\%) were found to have hemothorax injury and 45 (4\%) were found to have abdominal injury. Of these abdominal injuries, 30 (2.7\%) were found to have liver injury and 15 (1.3\%) were found to have spleen injury. Of the thoracic injuries, $25(2.2 \%)$ had single rib fracture, $7(0.6 \%)$ had 2-3 ribs fracture, $7(0.6 \%)$ had flail chest and $4(0.4 \%)$ had sternum fracture. Vascular injury was found in $9(0.8 \%)$ of the cases. One hundred and twenty-seven (11.3\%) of the cases had USG, 869 (77.5\%) had direct X-ray, 16 (1.4\%) had abdominal CT, 56 (5\%) had thoracic CT and 53 (4.7\%) had multiple imaging (Table 2). Age analysis of trauma types can be seen in Figure 1.

Mortality occurred in 23 (2\%) patients. Eighteen (1.6\%) of these were male. In lung involvement, while right and left lungs were equal with 3 cases, mortality was accompanied bilaterally in two cases. No mortality occurred in patients with contusion. In lumbar vertebra injury, while there was one mortality, no mortality was

\begin{tabular}{|c|c|c|c|c|}
\hline \multicolumn{5}{|c|}{ Age distribution } \\
\hline & All Patients & Min-max & Mean \pm SD & p-value \\
\hline \multicolumn{5}{|l|}{ Gender } \\
\hline Female & 379 & 19-90 & $39.26 \pm 15.91$ & \multirow[t]{2}{*}{0.007} \\
\hline Male & 742 & 19-94 & $42.14 \pm 16.95$ & \\
\hline \multicolumn{5}{|c|}{ Trauma } \\
\hline$-2 m F$ & 436 & 19-94 & $39.14 \pm 15.36$ & \multirow{5}{*}{0.001} \\
\hline$+2 \mathrm{mF}$ & 411 & 19-94 & $43.57 \pm 17.62$ & \\
\hline IVTA & 36 & 19-83 & $35.80 \pm 16.15$ & \\
\hline NVTA & 186 & $19-90$ & $40.13 \pm 16.24$ & \\
\hline $\mathrm{Pl}$ & 52 & $21-80$ & $46.56 \pm 17.64$ & \\
\hline \multicolumn{5}{|c|}{ Mortality } \\
\hline No & 1098 & 19-94 & $41.18 \pm 16.67$ & \multirow[t]{2}{*}{0.916} \\
\hline Yes & 23 & $20-67$ & $40.56 \pm 16.18$ & \\
\hline Total & 1121 & 19-94 & $41.17 \pm 16.15$ & \\
\hline
\end{tabular}


seen in thoracic vertebra, hemothorax, pneumothorax and vascular injuries. Most frequent mortality was found in spleen injury and patients who had direct X-ray (Table 3).

In both genders, $+2 \mathrm{mF}$ was the trauma in which imaging method was used the most. In contusions, thoracic CT was more frequent in thoracic traumas, while multiple imaging was more frequent in left and bilateral lung injuries. In thoracic traumas, thoracic CT was the most frequent imaging method. However multiple imaging was the most frequent in lumbal and thoracic vertebra, pneumothorax, hemothorax, abdominal and intraabdominal injuries and vascular injuries (Table 4). Figure 2 shows the graph of radiological imaging methods by age.
Correlation of trauma types was made with the variables. No correlation was found with age. However, weak or moderate positive correlation was found in all the other parameters (Table 5).

\section{Discussion}

Knowing about the trauma epidemiology is an effective way of evaluating morbidity and mortality. This way, risk groups are determined, it is easier to apply clinical treatment and the coordination of trauma type becomes easier (13). Each country should know about their trauma epidemiological factors. In the light of the data obtained, regional algorithms can be developed for trauma control and prevention of accident risk

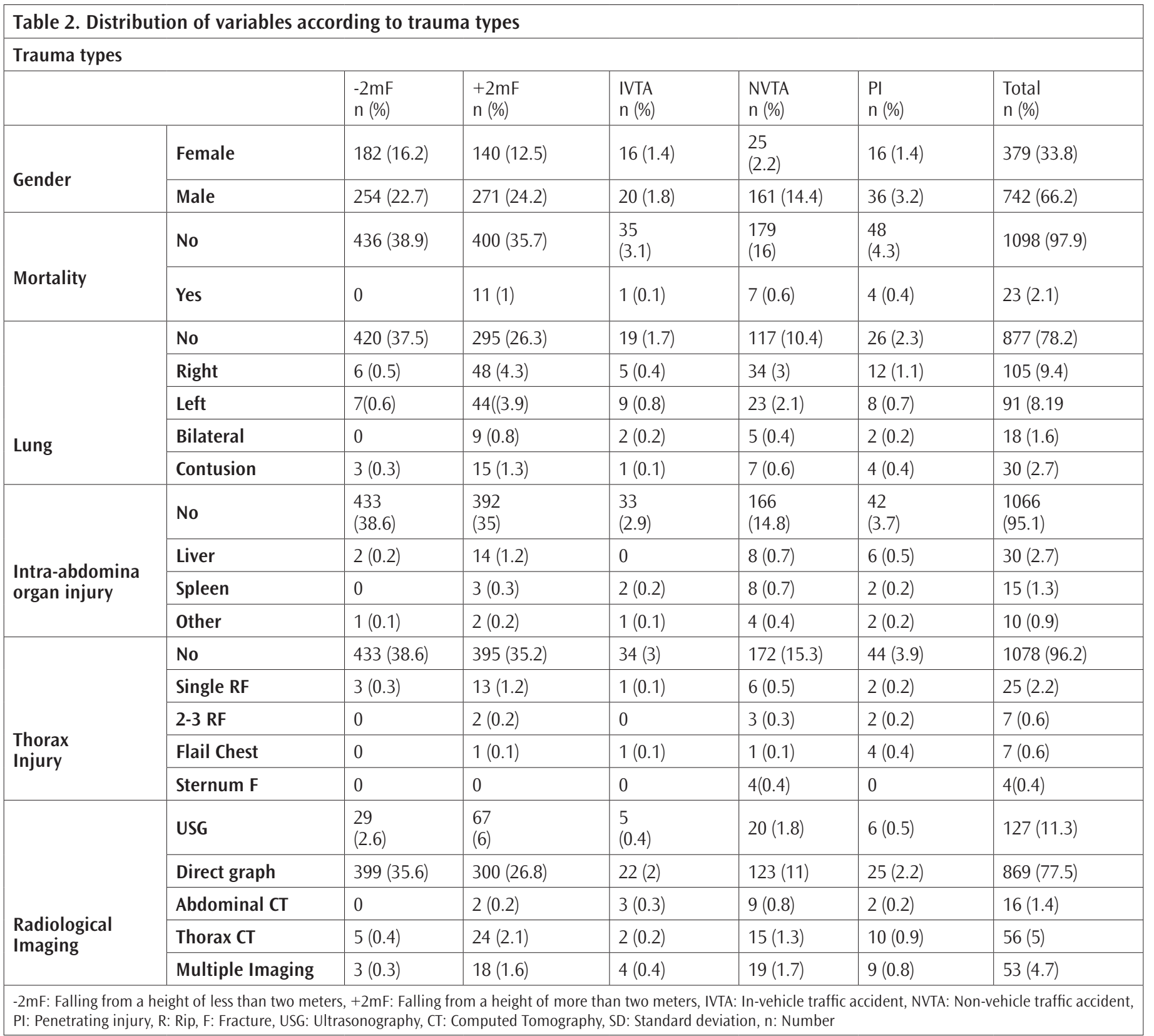




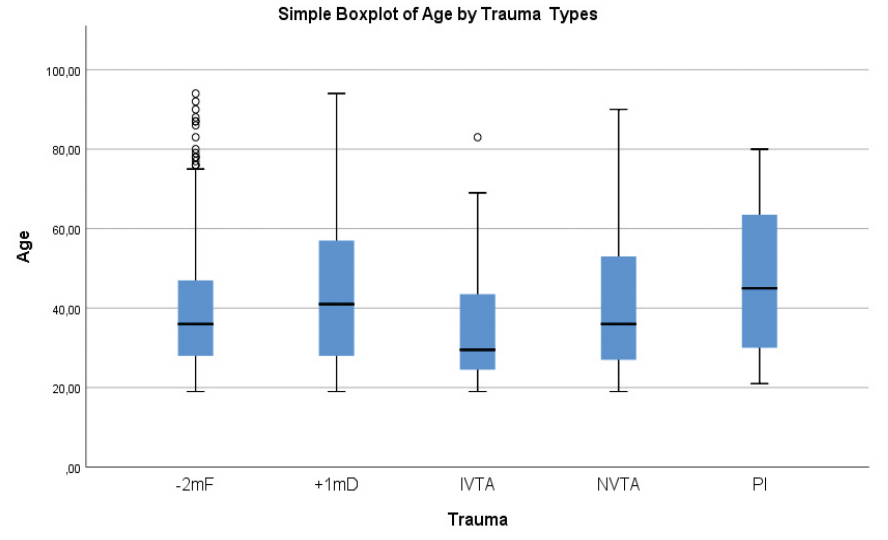

Figure 1. Distribution of age by trauma types

$-2 \mathrm{mF}$ : Falling from a height of less than two meters, $+2 \mathrm{mF}$ : Falling from a height of more than two meters, IVTA: In-vehicle traffic accident, NVTA: Non-vehicle traffic accident, PI: Penetrating injury (behavioural changes, informative legal campaigns, firearms control, prevention of falls in the elderly, speed limits) and for post-traumatic approaches.

Knowing about the trauma mechanism is important in terms of determining the first intervention of the patient in accident scene and hospital. In developed countries, the most common injury mechanisms are traffic accidents, falls and general blunt traumas, while penetrating traumas including gunshot and stabbing injuries are more common in developing countries due to on-going violence and social unrest $(7,10,11)$. Penetrating trunk trauma is the second leading cause of death after head trauma. Penetrating chest and abdominal trauma have high mortality rates when important structures such as the heart, great arteries and liver are involved at the scene (11-13). In a study, Larson stated that with the number of injured organs in

Table 3. Analysis of variables by mortality

\section{Mortality}

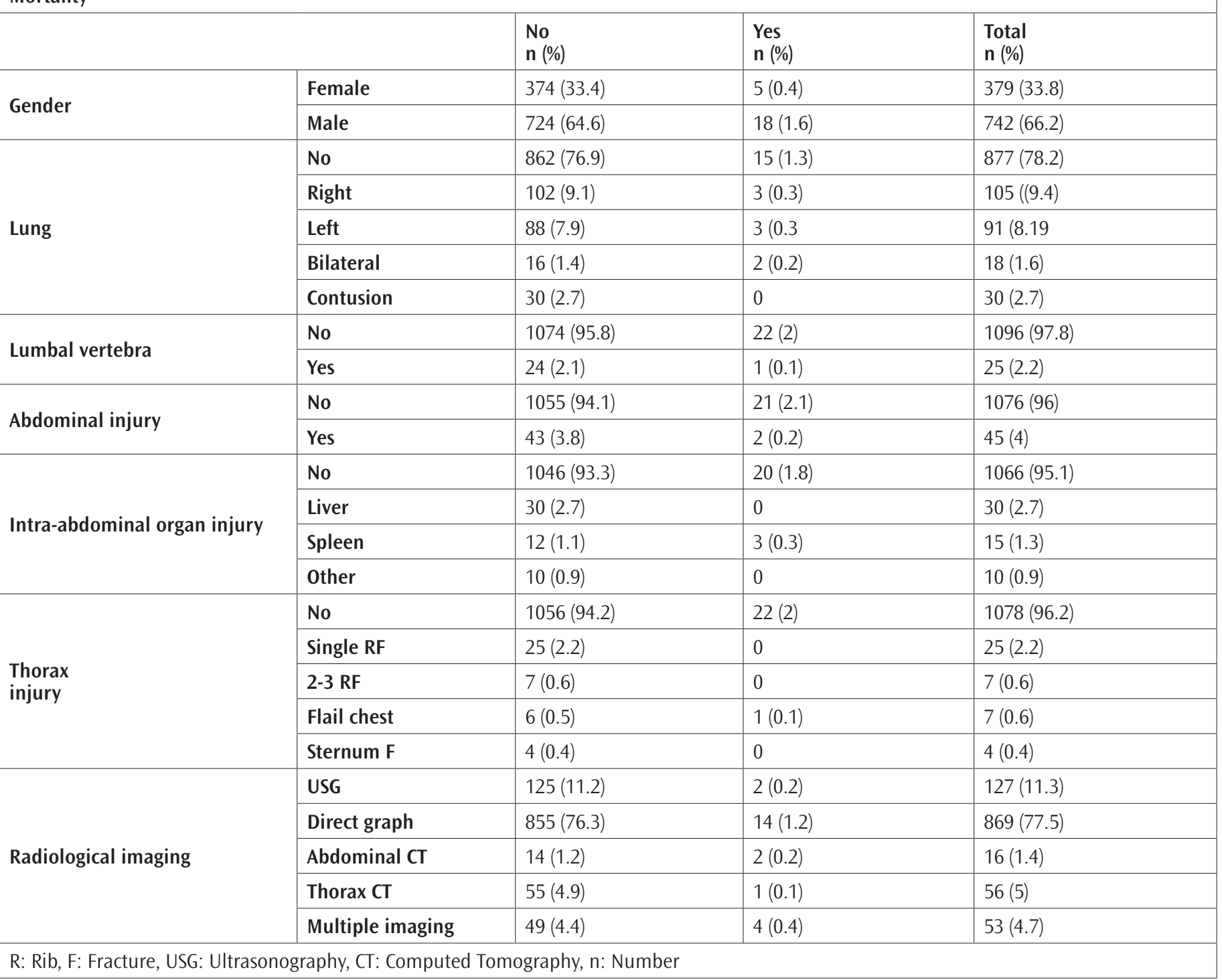




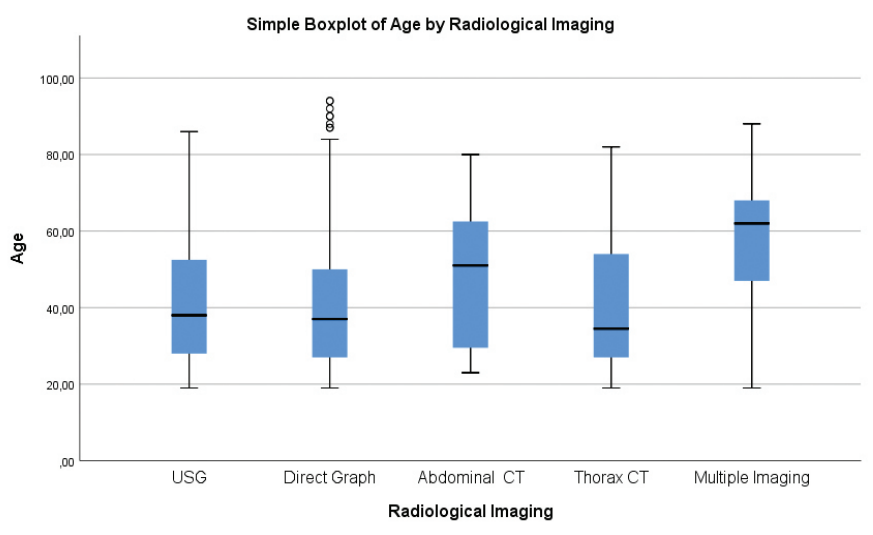

Figure 2. Distribution of age according to radiological imaging methods

USG: Ultrasonography, CT: Computed tomography penetrating traumas, the rate of complications that may develop also increases (14).

In our study, penetrating injury rates were found as $1.4 \%$ for women, 3.2\% for men and as $4.5 \%$ in total. Mortality rates were found higher in penetrating injuries, similar to previous studies. The rates of life-threatening thoracic trauma cases such as flail chest were found to be higher in our study in penetrating injuries.

Traffic accidents make up 35\% of trauma deaths worldwide. In addition, they are the most frequent cause of individual injuries after accident (15). While statistical rates increase in developing countries, they are lower in developed countries due to increased protective measures. Interestingly, while head traumas were found to be more common in young individuals in traffic accidents in low-income countries, they were found to

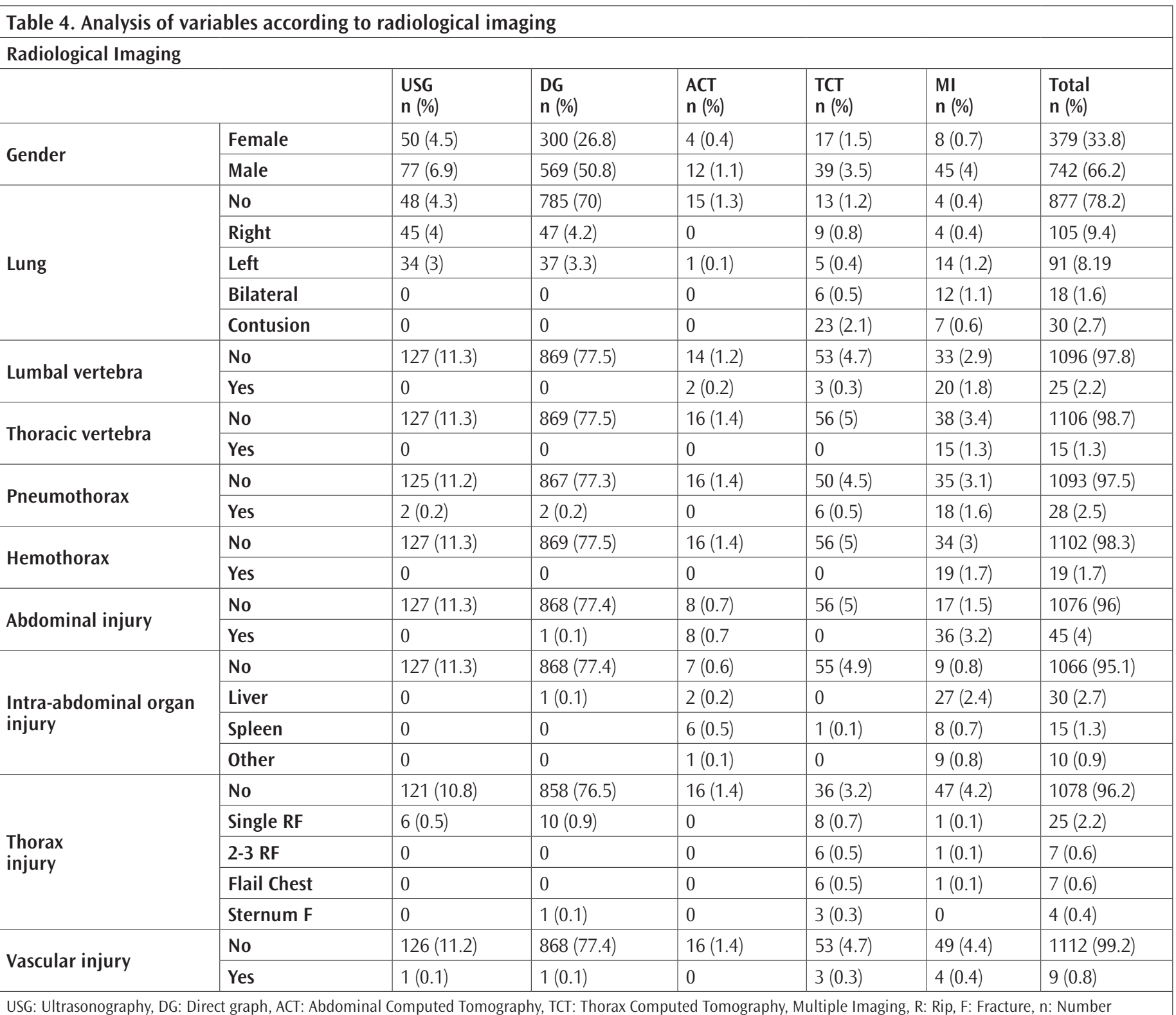




\begin{tabular}{|l|l|l|}
\hline Table 5. Correlation of variables with trauma types \\
\hline \multirow{2}{*}{ Correlation } & Trauma types & \multicolumn{2}{l|}{} \\
\cline { 2 - 3 } & $\mathrm{r}$ & $\mathrm{p}$-value \\
\hline Age & 0.050 & 0.092 \\
\hline Gender & 0.172 & 0.001 \\
\hline Madiological imaging & 0.245 & 0.001 \\
\hline Lung & 0.126 & 0.001 \\
\hline Lumbal vertebra & 0.278 & 0.001 \\
\hline Thoracic vertebra & 0.144 & 0.001 \\
\hline Pneumothorax & 0.059 & 0.048 \\
\hline Hemothorax & 0.172 & 0.001 \\
\hline Abdominal injury & 0.135 & 0.001 \\
\hline Intra-abdominal organ injury & 0.197 & 0.001 \\
\hline Thorax injury & 0.208 & 0.001 \\
\hline Vascular injury & 0.200 & 0.001 \\
\hline & 0.114 & 0.001 \\
\hline
\end{tabular}

be more common in elderly individuals in developed countries due to increased longevity rates and comorbidities of the elderly population $(7,16)$. In our study, in-vehicle traffic accident rates were lower than non-vehicle traffic accidents and mortality rates were lower. In addition, lung injury was found as $16.6 \%$ in non-vehicle traffic accidents and as 4.65 in penetrating injuries. Pneumothorax, hemothorax, sternum and more than two costal fracture cases were found to be in higher rates in non-vehicle traffic accidents.

In a meta-analysis by Stein et al. (17), it was found that mortality rates decreased by $50 \%$ in the last 150 years, while traffic accident rates continued to increase. Effective interventions are provided in trauma diagnosis and treatment due to advanced imaging techniques like computed axial tomography (4-6). In our study, while direct X-ray use was higher in falls from lower than $1 \mathrm{~m}, \mathrm{CT}$ and multiple imaging uses were higher respectively in non-vehicle traffic accidents, falls from higher than $1 \mathrm{~m}$ and penetrating injuries.

Falls from different levels constitute $44 \%$ of trauma cases (18). In our study, falls were evaluated in two groups. While rates of fall from lower than $1 \mathrm{~m}$ were $16.2 \%$ in women, $22.7 \%$ in men and $38.9 \%$ in total, the rates of fall from higher than $1 \mathrm{~m}$ were $12.5 \%$ in women, $24.2 \%$ in men and $36.7 \%$ in total. In previous studies, $33 \%-47 \%$ head traumas, $15 \%-26 \%$ extremity traumas and $8 \%-17 \%$ abdominal traumas were observed in fall-related accidents (19).

In their study on trauma mechanism, Magnone et al. (20) suggested that falling from the same level could be included in major trauma depending on the patient's age and clinical state $(20,21)$. It was shown that advanced age, hemodynamic imbalance, decreased consciousness and respiratory failure affected mortality regardless of trauma mechanism $(22,23)$.

Spleen is one of the most frequently injured solid organs of the abdominal cavity. Coccolini et al. (24) examined a total of 124 patients with spleen injury and the most frequent injury mechanism was found as blunt trauma secondary to traffic accidents, followed by falls. Spleen is one of the most frequently injured organs in blunt abdominal trauma, while its incidence reaches only $7 \%-9 \%$ in penetrating traumas (25). In spleen injuries, early diagnosis may decrease trauma-related mortality (26). In our study, spleen injury rates were found to be higher in non-vehicle traffic accident injuries when compared with other traumas. Liver injuries were observed in higher rates in falls from higher than $1 \mathrm{~m}$.

\section{Study Limitations}

One of the limitations of the study is the fact that the data were obtained from a single centre and retrospectively and the data intervals were limited in some patient groups. Another limitation was the fact that there may be loss in patient information and post-treatment follow-up.

\section{Conclusion}

The results obtained in our study will enable intervention without losing time in trauma area or in hospital in terms of triage and treatment of patients. Thus, it will be possible to prevent trauma-related mortality and morbidity in young and 
productive age group of the society. We think that advances in radiological imaging can reduce both mortality and morbidity.

\section{Ethics}

Ethics Committee Approval: This study was approved by Clinical Researches Ethics Committee of Cumhuriyet University (decision no: 2019-12/22, date: 11.12.2019), it was carried out in accordance with Helsinki declaration for human researches.

Informed Consent: Retrospective study.

Peer-review: Externally peer-reviewed.

\section{Authorship Contributions}

Surgical and Medical Practices: F.T.T., Concept: F.T.T., A.C., Design: A.C., Data Collection or Processing: A.C., Analysis or Interpretation: F.T.T., A.C., Literature Search: F.T.T., Writing: F.T.T.

Conflict of Interest: No conflict of interest was declared by the authors.

Financial Disclosure: The authors declared that this study received no financial support.

\section{References}

1. Department of Violence, Injury Preventionand Disability. Injuriesand Violence. The Facts. Geneva: World Health Organization, 2004:1-160.

2. Lin M, Kolosh KP, Fearn K. Injury Facts. Itasca: National Safety Council, 2011:1-6.2. The National Confidential Enquiryinyo Patient Outcome and Death. Trauma 2007. Available at: https://www.yumpu.com/en/document/ read/27268831/injury-facts-2011-w-national-safety-council

3. Henry JA, Reingold AL. Prehospital trauma systems reduce mortality in devoloping countries: a systemic review and meta-analysis. J Trauma Acute Care Surg. 2012:73:261-8.

4. Holcomb JB, Wade CE, Brasel KJ, Vercruysse G, MacLeod J, Dutton RP, et al. Defining present blood component transfusion practices in trauma patients: papers from the Trauma Outcomes Group. J Trauma. 2011;71:315-7.

5. Ferre A. The value of life. J Trauma Acute Care Surg. 2021;91:23.

6. Kauvar DS, Wade CE. The epidemiology and modern management of traumatic haemorrhage: US and interventional perspectives. Crit Care. 2005;9:1-9.

7. Alberdi F, García I, Atutxa L, Zabarte M; Trauma and Neurointensive Care Work Group of the SEMICYUC. Epidemiology of severe trauma. Med Intensiva. 2014;38:580-8.

8. Hansen KS, Morild I, Engesaeter LB, Viste A. Epidemiology of severely and fatally injured patients in western part of Norway. Scand J Surg. 2004;93:198203.
9. Okuş A, Sevinç B, Ay S, Arslan K, Karahan Ö, Eryılmaz MA. Conservative management of abdominal injuries. Ulus Cerrahi Derg. 2013;29:153-7.

10. Pooria A, Pourya A, Gheini A. A Descriptive Study on the Usage of Exploratory Laparotomy for Trauma Patients. Open Access Emerg Med. 2020;12:255-60.

11. Millán M, Ordoñez CA, Parra MW, Caicedo $Y$, Padilla N, Pino LF, et al. Hemodynamically unstable non-compressible penetrating torso trauma: a practical surgical approach. Colomb Med (Cali). 2021;52:e4024592.

12. Lefering R, Paffrath T, Bouamra O, Coats TJ, Woodford M, Jenks T, et al. Epidemiology of in-hospital trauma deaths. Eur J Trauma Emerg Surg. 2012;38:3-9.

13. DiMaggio CJ, Avraham JB, Lee DC, Frangos SG, Wall SP. The Epidemiology of emergency department trauma discharges in the United States. Acad Emerg Med. 2017;24:1244-56

14. Larson CR, White CE, Spinella PC, Jones JA, Holcomb JB, Blackbourne LH, et al. Association of shock, coagulopathy, and initial vital signs with massive transfusion in combat casualties. J Trauma. 2010;69:26-32.

15. Sharma BR. Road traffic injuries: a major global public health crisis. Public Health. 2008;122:1399-406.

16. MRC CRASH Trial Collaborators. Predicting outcome after traumatic brain injury: practical prognostic models based on large cohort of international patients. BMJ. 2008;336:425-9.

17. Stein SC, Georgoff P, Meghan S, Mizra K, Sonnad SS. 150 years of treating severe traumatic brain injury: a systematic review of progress in mortality. I Neurotrauma. 2010;27:1343-53.

18. National Trauma Data Bank (NTDB) Annual Report. American College of Surgeons; 2012. Available at: https://www.facs.org/quality-programs/ trauma/tqp/center-programs/ntdb

19. Roozenbeek B, Maas AI, Menon DK. Changing patterns in the epidemiology of traumatic brain injury. Nat Rev Neurol. 2013;9:231-6.

20. Magnone S, Ghirardi A, Ceresoli M, Ansaloni L. Trauma patients centralization for the mechanism of trauma: old questions without answers. Eur J Trauma Emerg Surg. 2019;45:431-6.

21. Gu F, Zhou J, Bian W, Ding J, Zou M, Lu S, et al. Effect of predictive trauma care on fracture healing and complications of traumatic fracture patients in emergency department. Am J Transl Res. 2021;13:3752-8.

22. Thompson L, Hill M, McMeekin P, Shaw G. Defining major trauma: a prehospital perspective using focus groups. Br Paramed J. 2019;4:16-23.

23. Gioffrè-Florio M, Murabito LM, Visalli C, Pergolizzi FP, Famà F. Trauma in elderly patients: a study of prevalence, comorbidities and gender differences. G Chir. 2018;39:35-40.

24. Coccolini F, Montori G, Catena F, Kluger Y, Biffl W, Moore EE, et al. Splenic trauma: WSES classification and guidelines for adult and pediatric patients. World J Emerg Surg. 2017;12:40.

25. Serna C, Serna JJ, Caicedo Y, Padilla N, Gallego LM, Salcedo A, et al. Damage control surgery for splenic trauma: "preserve an organ - preserve a life". Colomb Med (Cali). 2021;52:e4084794.

26. Orhon R, Eren SH, Karadayı S, Korkmaz I, Coskun A, Eren M, et al. Comparison of trauma scores for predicting mortality and morbidity on trauma patients. Ulus Travma Acil Cerrahi Derg. 2014;20:258-64. 